Supporting Information for

\title{
Methane Transformation over Copper-exchanged Zeolites: from Partial Oxidation to C-C Coupling and Formation of Hydrocarbons
}

Mikalai A. Artsiusheuskia, ${ }^{a, b}$ René Verel $^{b}$, Jeroen A. van Bokhoven ${ }^{a, b, *}$, Vitaly L. Sushkevich ${ }^{\mathrm{b}, *}$

a Laboratory for Catalysis and Sustainable Chemistry, Paul Scherrer Institut, 5232

Villigen PSI, Switzerland

${ }^{b}$ Institute for Chemistry and Bioengineering, ETH Zurich, Vladimir-Prelog-Weg 1, 8093 Zurich, Switzerland

*Corresponding authors: Tel.: +41563103518; E-mail address:

jeroen.vanbokhoven@chem.ethz.ch,vitaly.sushkevich@psi.ch,
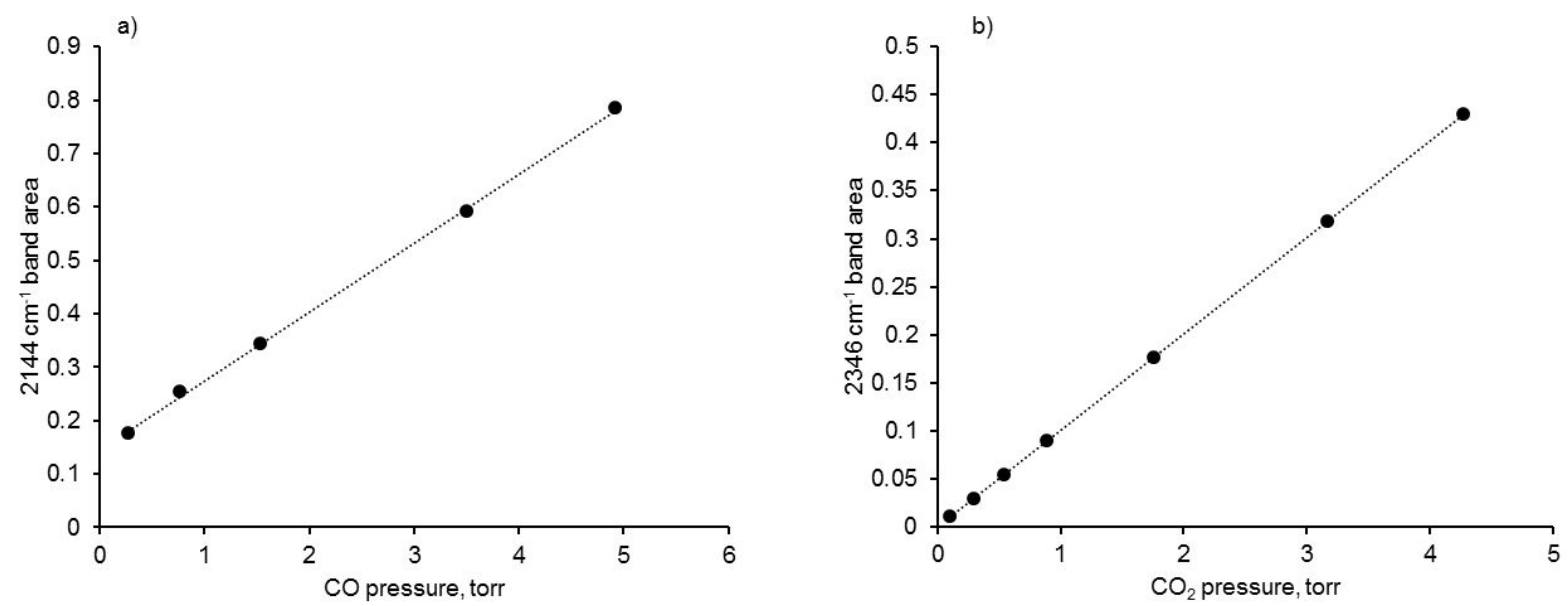

Figure S1. Calibration curves for a) carbon monoxide and b) carbon dioxide used for quantitate analysis of the gas phase.

The effect of the evacuation temperature on the nature and amount of surface species detected by means of FTIR spectroscopy

To establish the possible effect of the evacuation temperature on the nature and the amount of the surface species formed over the samples after reaction with methane, additional experiments were performed with evacuation of the gas phase at higher temperature. Namely, after the reaction with methane, the sample was not cooled down 
to the ambient temperature, but the evacuation of the gas phase was carried out at the temperature of reaction for 5 minutes to the residual pressure about $5 \cdot 10^{-6}$ torr. The comparison of the FTIR spectra of surface species detected after the evacuation at the ambient temperature (blue lines) and at the reaction temperature (red lines) for $\mathrm{Cu}(3.4) \mathrm{MOR}(10), \mathrm{Cu}(4.0) \mathrm{MFI}(12), \mathrm{Cu}(2.8) \mathrm{BEA}(12)$ and $\mathrm{Cu}(2.7)$ FAU(15) samples is presented in Figures $\mathrm{S} 2$ a)-d), respectively. For $\mathrm{Cu}(3.4) \mathrm{MOR}(10)$ sample the spectrum without the evacuation of the gas phase was acquired and is given in Figure S2 a) in green. The reaction temperature is $523 \mathrm{~K}$ for $\mathrm{Cu}(3.4) \mathrm{MOR}(10)$ and $\mathrm{Cu}(4.0) \mathrm{MFI}(12)$ samples and for $623 \mathrm{~K}$ for $\mathrm{Cu}(2.8) \mathrm{BEA}(12)$ and $\mathrm{Cu}(2.7) \mathrm{FAU}(15)$. 

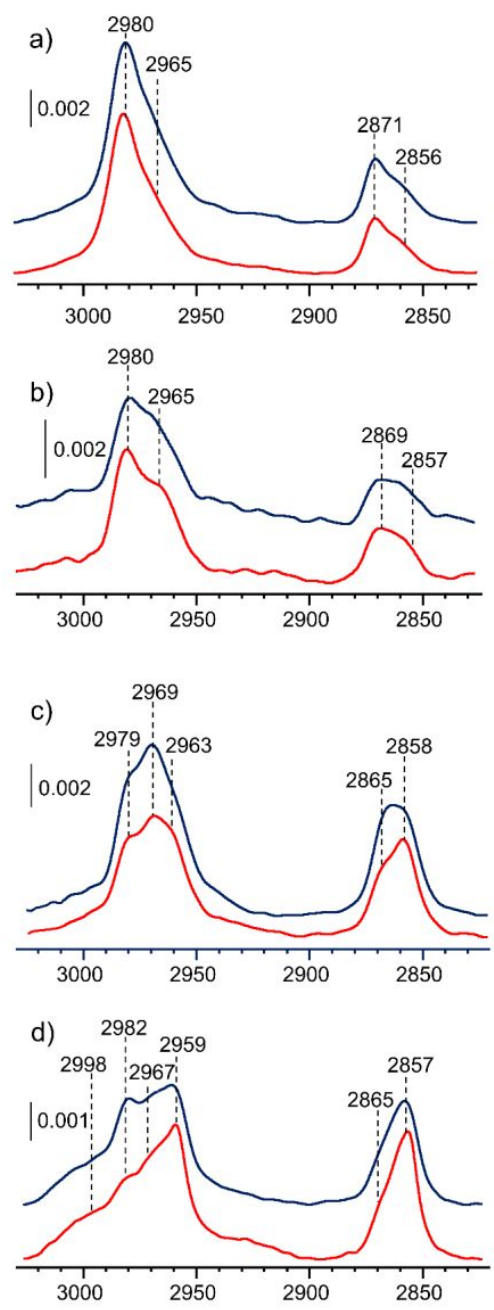
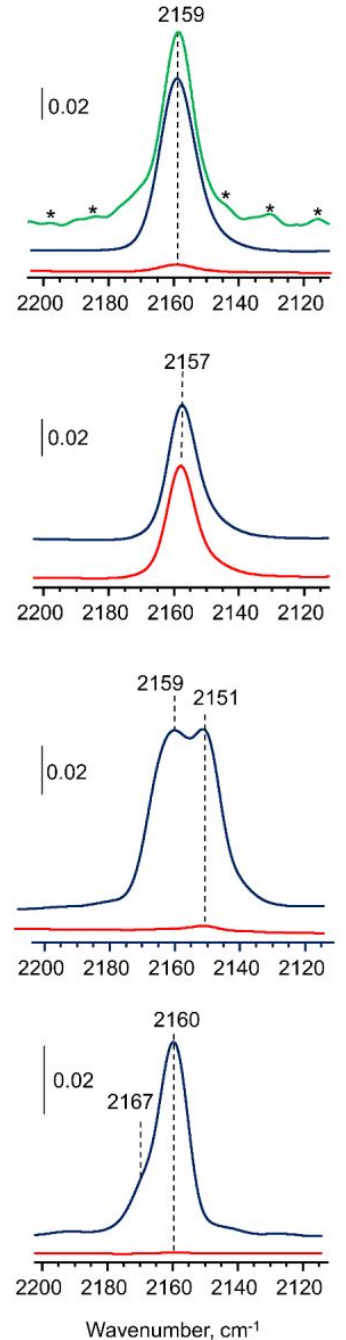
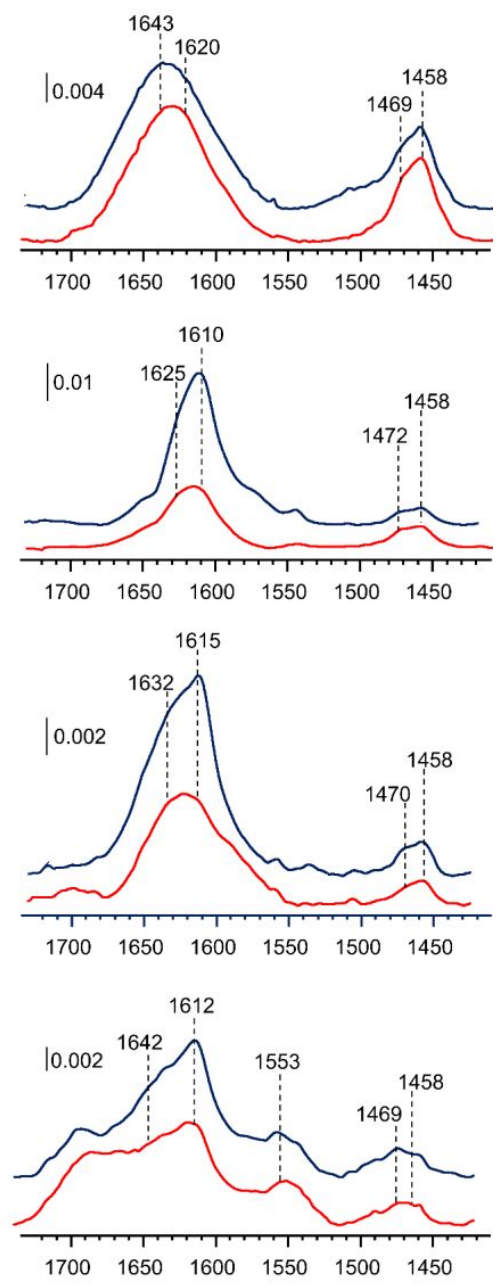

Figure S2. FTIR spectra of surface species after the evacuation of the gas phase at ambient temperature (blue lines) and at reaction temperature (red lines) over a) $\mathrm{Cu}(3.4) \mathrm{MOR}(10) \mathrm{b}$ ) $\mathrm{Cu}(4.0) \mathrm{MFI}(12) \mathrm{c}) \mathrm{Cu}(2.8) \mathrm{BEA}(12)$ and d) $\mathrm{Cu}(2.7) \mathrm{FAU}(15)$. Green line in a) corresponds to spectrum without the evacuation of the gas phase. Asterisks denote the bands from the gas phase methane.

The comparison of the spectra shows that the position of the bands is not affected by the evacuation temperature pointing to the identical nature of the formed surface species. Moreover, for all the samples the intensity of the bands due to adsorbed methanol and methoxy species in the spectra corresponding to the evacuation at ambient temperature is similar to that in spectra acquired after evacuation at reaction temperature. 
At the same time, the evacuation at high temperature leads to significant decrease of the intensity of carbonyl bands for all samples, except for $\mathrm{Cu}(4.0) \mathrm{MFI}(12)$, due to the decomposition of carbonyls in vacuum. To examine the possibility of carbonyls decomposition at ambient temperature, the intensity of carbonyl band prior to the evacuation of the gas phase was measured for $\mathrm{Cu}(3.4) \mathrm{MOR}(10)$ sample (Figure S2 a, green line) and was found to be equal to that in the spectrum acquired after the evacuation of the gas phase at ambient temperature. This shows that the evacuation at ambient temperature after the reaction does not lead to any change in the nature or amount of formed surface products.

\section{The possible effect of the adsorption of oxygenates on the state of copper atoms}

To examine the possible effect of the adsorption of the reaction products on the state of copper atoms we used X-ray Absorption Spectroscopy (XAS) at Cu K-edge. The measurements were performed at the SuperXAS beamline at the Swiss Light Source (Switzerland). The X-ray beam, the sample, and the X-ray detectors were in conventional transmission geometry mode. The spectrum of a copper foil was collected for the energy calibration. Reduced $\mathrm{Cu}(3.4) \mathrm{MOR}(10)$ sample was prepared according to the following procedure: about $20 \mathrm{mg}$ of the material were placed into quartz capillary with wall thickness of $0.01 \mathrm{~mm}$ and connected to the vacuum system. Afterwards, activation in 400 torr of oxygen at $673 \mathrm{~K}$ for $2 \mathrm{~h}$ was carried out. Then the material was evacuated at $673 \mathrm{~K}$ up to the residual pressure $2 \cdot 10^{-6}$ torr, followed by the reduction in 200 torr of carbon monoxide at $673 \mathrm{~K}$ for $1 \mathrm{~h}$. Final evacuation was carried out at $673 \mathrm{~K}$ for $2 \mathrm{~h}$. Obtained material was denoted as " $\mathrm{Cu}(3.4) \mathrm{MOR}(10)$ red". Separately, methanol or formic acid in amount corresponding to $300 \mu \mathrm{mol} \cdot \mathrm{g}^{-1}$ were 
adsorbed over pre-reduced material, and the samples were sealed and denoted as “ $\mathrm{Cu}(3.4) \mathrm{MOR}(10) \_$red_MeOH” and " $\mathrm{Cu}(3.4) \mathrm{MOR}(10)$ _red_HCOOH”, respectively. XAS spectra of $\mathrm{Cu}(3.4) \mathrm{MOR}(10) \_$red, $\quad \mathrm{Cu}(3.4) \mathrm{MOR}(10) \_$red_MeOH and $\mathrm{Cu}(3.4) \mathrm{MOR}(10) \_$red_HCOOH samples are presented in Figure S3.

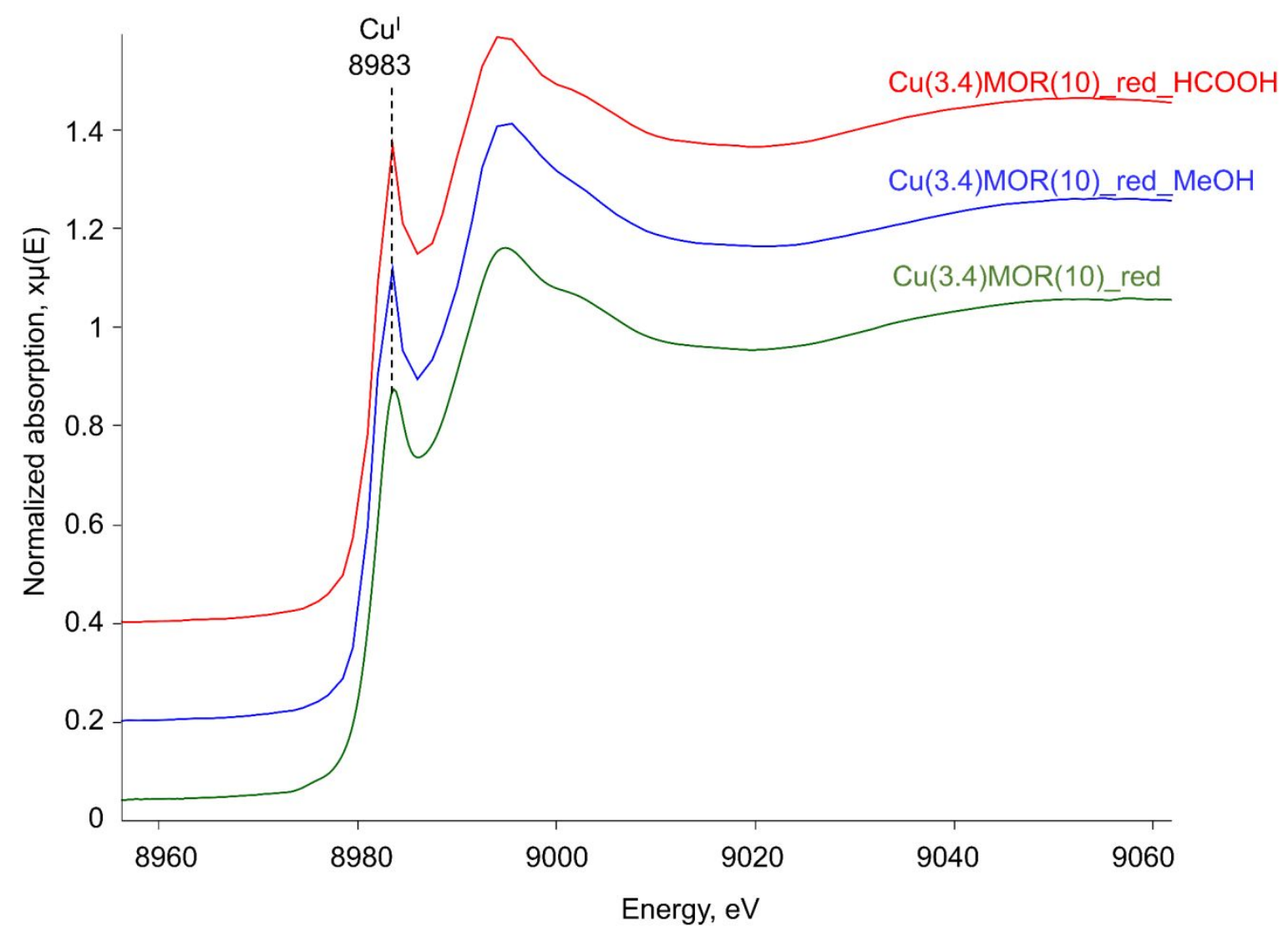

Figure S3. Cu K-edge XANES spectra of $\mathrm{Cu}(3.4) \mathrm{MOR}(10)$ red sample: as prepared, after the adsorption of methanol and after the adsorption of formic acid.

The presence of the intense signal at $8983 \mathrm{eV}$ and absence of the signals at 8977 and $8986 \mathrm{eV}$ in the spectra corresponding to $\mathrm{Cu}(3.4) \mathrm{MOR}(10)$ _red sample shows almost complete conversion of $\mathrm{Cu}^{\mathrm{II}}$ into $\mathrm{Cu}^{\mathrm{I}}$. No signals due to $\mathrm{Cu}^{0}$ were found. Adsorption of methanol and formic acid does not lead to any notable changes in XANES spectra indicating that the oxidation state of copper atoms and its coordination environment do not undergo any changes. 
The composition of the gas phase during the temperature programmed reaction between copper-exchanged zeolites and methane
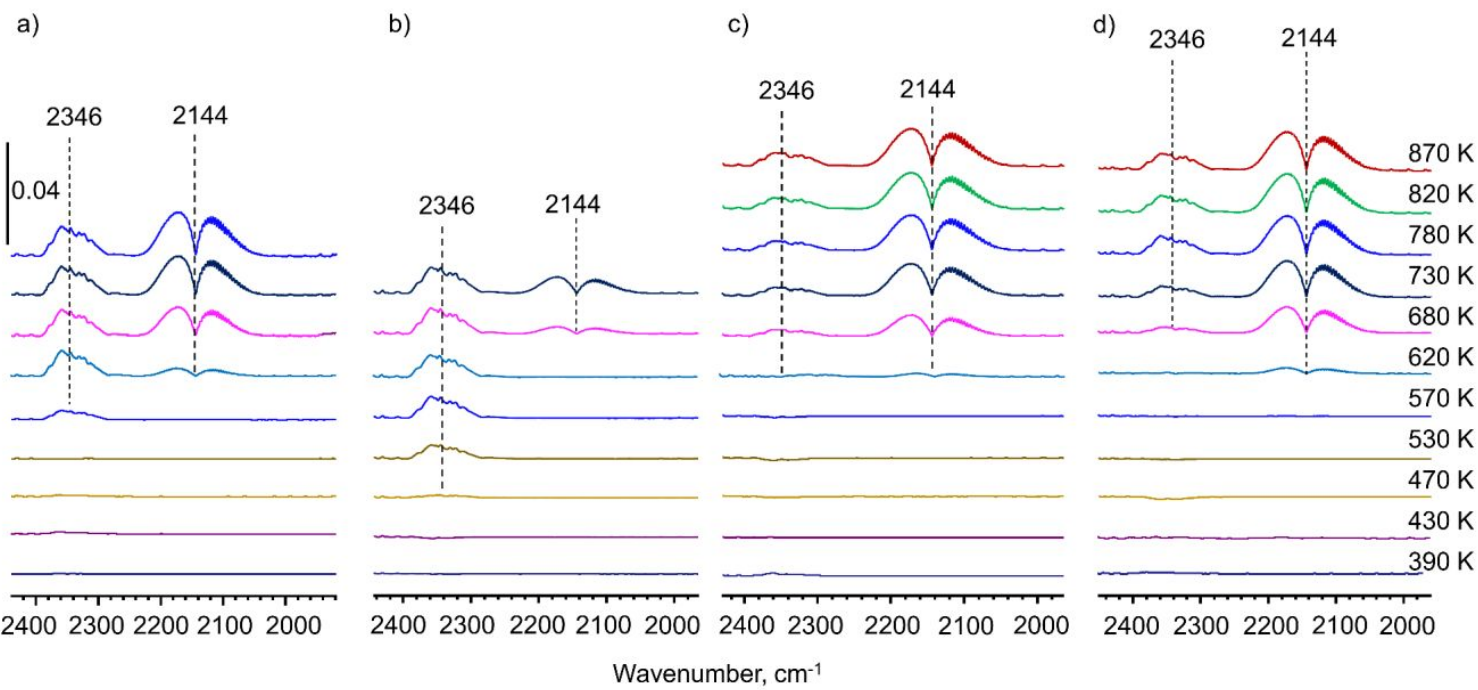

Figure S4. FTIR spectra of gas phase during the temperature programmed reaction of 200 torr of methane with a) $\mathrm{Cu}(3.4) \mathrm{MOR}(10)$ b) $\mathrm{Cu}(4.0) \mathrm{MFI}(12) \mathrm{c}) \mathrm{Cu}(2.8) \mathrm{BEA}(12)$ and d) $\mathrm{Cu}(2.7) \mathrm{FAU}(15)$.

\section{Reactivity test of copper-exchanged zeolites:}

Methane conversion over copper-exchanged zeolites was studied using standard protocol $^{1-3}$. For the experiment, $200 \mathrm{mg}$ of sample in form of $0.25-0.5 \mathrm{~mm}$ fraction were put into stainless steel plug-flow reactor, heated in a flow of oxygen $\left(40 \mathrm{ml} \cdot \mathrm{min}^{-1}\right)$ to $673 \mathrm{~K}$ at $1 \mathrm{bar}$ for $1 \mathrm{~h}$ with heating rate of $5 \mathrm{~K} \cdot \mathrm{min}^{-1}$ for activation. The activated sample was cooled to the desired temperature with cooling rate of $10 \mathrm{~K} \cdot \mathrm{min}^{-1}$ in a flow helium $\left(40 \mathrm{ml} \cdot \mathrm{min}^{-1}\right)$ to remove the traces of oxygen. Then, a flow of methane $\left(50 \mathrm{ml} \cdot \mathrm{min}^{-1}\right)$ was introduced to the reaction with activated CuMOR and the total pressure was increased to 8 bars. After $30 \mathrm{~min}$ of the reaction, the methane pressure was released and the reactor was cooled in a helium flow $\left(40 \mathrm{ml} \cdot \mathrm{min}^{-1}, 1 \mathrm{bar}\right)$ to the $473 \mathrm{~K}$. The methane conversion products were desorbed by interaction of sample with a wet stream of helium (40 $\mathrm{ml} \cdot \mathrm{min}^{-1}, 1$ bar), prepared by bubbling through the saturator with liquid water kept 
at $29 \mathrm{~K}$ (resulting in partial pressure of water equal to 0.025 bar). After the desorption of methanol ( 3 hours) the reactor was purged with dry helium $\left(40 \mathrm{ml} \cdot \mathrm{min}^{-1}\right)$ for $10 \mathrm{~min}$ and heated up to $673 \mathrm{~K}$ with the heating rate of $3 \mathrm{~K} \cdot \mathrm{min}^{-1}$ in dry helium to desorb $\mathrm{CO}_{2}$. Carbon products were detected with micro-GC equipped with TCD detector and molecular sieves (MS5) and Porapak Q (PPQ) columns, the analysis of the gas phase was performed with time intervals of 2 minutes. Profiles for the concentrations of the reaction products formed over $\mathrm{Cu}(3.5) \mathrm{MOR}(10)$ during the desorption procedure are presented in figure S5. The total amount of the formed products was calculated by integration of the obtained curves. The total amount of the methoxy species was calculated as sum of the amount of methanol and doubled the amount of DME, since the latter contain two carbon atoms. Unfortunately, hydrocarbons were not detected during the steam-assisted desorption stage of the reactivity tests. Apparently, they do not adsorb on the surface of the active materials and are quickly removed from the reactor during the flushing with inert gas or/and methane. Therefore, to estimate the amount of the formed hydrocarbons, the procedure based on the integration of the ${ }^{13} \mathrm{C}$ HPDEC NMR spectra was applied. 


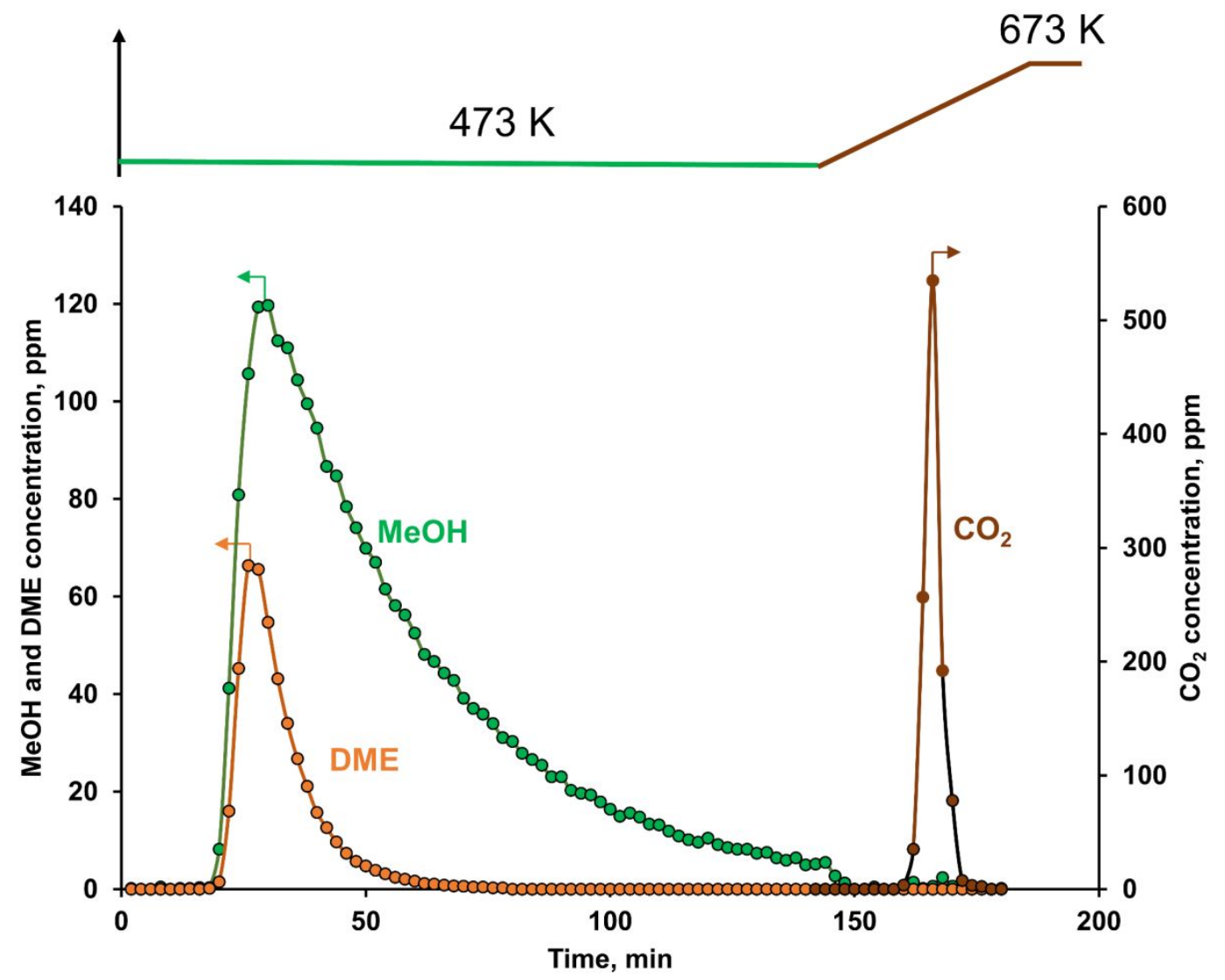

Figure S5. Concentration of the products in the gas phase during the steam-assisted desorption at $473 \mathrm{~K}$ for $\mathrm{Cu}(3.4) \mathrm{MOR}(10)$ sample.

\section{Quantitative analysis of the NMR spectra:}

The intensity of the signals in the single-pulse NMR, namely ${ }^{1} \mathrm{H}$ and ${ }^{13} \mathrm{C}$ HPDEC, is directly proportional to the number of atoms, a priory allowing the integration of spectra to determine the number of the Brønsted acid sites or the amount of formed carbon-containing products based on ${ }^{1} \mathrm{H}$ and ${ }^{13} \mathrm{C}$ HPDEC spectra, respectively. However, in the case of methane conversion over copper-exchanged zeolites such a direct quantification is extremely challenging due to the presence of paramagnetic $\mathrm{Cu}^{\mathrm{II}}$ species that suppress the signals. The careful quantitative analysis is only possible for the spectra acquired at high conversion of $\mathrm{Cu}^{\mathrm{II}}$ to $\mathrm{Cu}^{\mathrm{I}}$ atoms, i.e. spectra corresponding to the high reaction temperature. As the result, the analysis of the amount of the Brønsted acid sites in unreacted materials is ambiguous. Additional limitation in the 
quantification of the formed products comes from the fact that the signal from methane cannot be used as internal standard due to its suppression by $\mathrm{Cu}^{\mathrm{II}}$ in the spectra corresponding to low reaction temperature and partial methane conversion at higher reaction temperature.

In order to determine the amount of the products, the following procedure was applied. First, for each sample we determined the temperature at which the highest intensity of signals due to the partial oxidation products, namely methanol, methoxy species and DME, is observed. We supposed that the conversion of $\mathrm{Cu}^{\mathrm{II}}$ to $\mathrm{Cu}^{\mathrm{I}}$ at this and higher reaction temperatures is sufficient to allow the direct integration of the signals in ${ }^{13} \mathrm{C}$ HPDEC spectra. Next, for each sample we performed the reactivity test at the temperature corresponding to the highest yield according to NMR spectroscopy, and determined the amount of formed methanol and DME. Finally, we used the obtained values of methanol and DME productivity and the intensity of corresponding signals in ${ }^{13} \mathrm{C}$ HPDEC spectra to calculate the amounts of hydrocarbons and carbon dioxide formed at high reaction temperature. The amounts were calculated according to the following expression: $n(X)=n(M e O) \cdot \frac{I(X)}{I(\Sigma M e O)}$, where $n(X)$ corresponds to the desired amount of hydrocarbons or carbon dioxide $\left(\mu \mathrm{mol} \cdot \mathrm{g}^{-1}\right), n(\mathrm{MeO})$ is the sum of the amount of methanol and doubled amount of DME determined from reactivity test $\left(\mu \mathrm{mol} \cdot \mathrm{g}^{-1}\right), I($ $\Sigma \mathrm{MeO}$ ) is the sum of the intensities of the signals due to adsorbed methanol, methoxy species and DME, and $I(X)$ is the intensity of the signal corresponding to hydrocarbons or carbon dioxide. The results of the reactivity tests and the amounts of carbon dioxide and hydrocarbon molecules estimated from ${ }^{13} \mathrm{C}$ HPDEC spectra are presented in Table S1. 
Table S1. Amount of products formed over copper-exchanged zeolites

\begin{tabular}{|c|c|c|c|c|c|c|}
\hline \multirow{2}{*}{ Sample } & \multicolumn{2}{|c|}{ Reactivity test } & \multicolumn{4}{|c|}{$\begin{array}{c}\text { Amount of products estimated from }{ }^{13} \mathrm{C} \\
\text { HPDEC NMR spectra, } \mu \mathrm{mol} \cdot \mathrm{g}^{-1}\end{array}$} \\
\cline { 2 - 8 } & $\mathrm{T}, \mathrm{K}$ & $\begin{array}{c}n(\mathrm{MeO}), \\
\mu \mathrm{mol} \cdot \mathrm{g}^{-1}\end{array}$ & $\begin{array}{c}\text { Reaction } \\
\text { temperature, } \mathrm{K}\end{array}$ & Ethane & Propane & $\mathrm{CO}_{2}$ \\
\hline $\mathrm{Cu}(3.4) \operatorname{MOR}(10)$ & 548 & 112 & 673 & 5 & 1 & $<0.5$ \\
\hline $\mathrm{Cu}(4.0) \operatorname{MFI}(12)$ & 548 & 30 & 648 & $<0.3$ & $<0.3$ & 12 \\
\hline $\mathrm{Cu}(2.8) \mathrm{BEA}(12)$ & 623 & 54 & 723 & 4 & 1.5 & 15 \\
\hline $\mathrm{Cu}(2.7) \mathrm{FAU}(15)$ & 648 & 27 & 748 & 2 & 2 & 2 \\
\hline
\end{tabular}

The temperatures corresponding to the highest yield of partial oxidation products based on NMR spectroscopy are higher compared to similar values obtained from FTIR spectroscopy due to the presence of unreacted $\mathrm{Cu}^{\mathrm{II}}$ atoms which suppress the signals. However, the general trend within the studied set of samples is the same as observed by means of FTIR spectroscopy: $\mathrm{Cu}(4.0) \mathrm{MFI}(12)$ and $\mathrm{Cu}(3.4) \mathrm{MOR}(10)$ samples start to produce methanol at lower temperatures compared to $\mathrm{Cu}(2.8) \mathrm{BEA}(12)$ and $\mathrm{Cu}(2.7) \mathrm{FAU}(15)$.

The effect of paramagnetic $\mathrm{Cu}^{\mathrm{II}}$ on the position and the width of methane signal in

\section{${ }^{13}$ C HPDEC NMR spectra}

Different initial position of the methane signal in ${ }^{13} \mathrm{C}$ HPDEC NMR spectra, namely $\sim 4 \mathrm{ppm}$ for $\mathrm{Cu}(3.4) \mathrm{MOR}(10)$ and $\mathrm{Cu}(4.0) \mathrm{MFI}(12)$ and $\sim 2 \mathrm{ppm}$ for $\mathrm{Cu}(2.8) \mathrm{BEA}(12)$ and $\mathrm{Cu}(2.7) \mathrm{FAU}(15)$, and different width of the signals we associate with the nature of copper-oxo species in zeolites. Thus, in mordenite copper preferentially forms isolated monomers ${ }^{4,5}$, resulting in high number of paramagnetic species. As a result, methane peak is significantly shifted due to paramagnetic pseudocontact shift and all peaks are broadered. The smallest size of the channel system in MFI compared to others studied zeolites ${ }^{6}$ enable close contact of methane molecule with 
$\mathrm{Cu}^{\mathrm{II}}$ paramagnetic species, which also leads to high value of pseudo-contact shift. In large-pore FAU and BEA zeolites contact of methane molecules and $\mathrm{Cu}^{\mathrm{II}}$ species is less close compared to copper-exchanged MOR and MFI. Moreover, in BEA and FAU zeolites formation of copper-oxo clusters takes place ${ }^{5}$, resulting decrease of the number of paramagnetic species. Therefore, observed for methane paramagnetic pseudo-contact shift is lower and peaks are sharper.

\section{References:}

(1) Mae Alayon, E.; Nachtegaal, M.; Ranocchiari, M.; Van Bokhoven, J. A. Catalytic Conversion of Methane to Methanol over Cu-Mordenite. Chem. Commun. 2012, 48 (3), 404-406. https://doi.org/10.1039/c1cc15840f.

(2) Tomkins, P.; Ranocchiari, M.; Van Bokhoven, J. A. Direct Conversion of Methane to Methanol under Mild Conditions over Cu-Zeolites and Beyond. Acc. Chem. Res. 2017, 50 (2), 418-425. https://doi.org/10.1021/acs.accounts.6b00534.

(3) Sushkevich, V. L.; Van Bokhoven, J. A. Methane-to-Methanol: Activity Descriptors in Copper-Exchanged Zeolites for the Rational Design of Materials. ACS Catal. 2019, 9 (7), 6293-6304. https://doi.org/10.1021/acscatal.9b01534.

(4) Sushkevich, V. L.; Palagin, D.; van Bokhoven, J. A. The Effect of the Active-Site Structure on the Activity of Copper Mordenite in the Aerobic and Anaerobic Conversion of Methane into Methanol. 2018, No. 29.

(5) Sushkevich, V. L.; Safonova, O. V.; Palagin, D.; Newton, M. A.; van Bokhoven, J. A. Structure of Copper Sites in Zeolites Examined by Fourier and Wavelet Transform Analysis of EXAFS. Chem. Sci. 2020, 11 (20), 5299-5312. https://doi.org/10.1039/d0sc01472a.

(6) Database of Zeolite Structures http://www.iza-structure.org/databases/ 